\title{
PADRÕES DE DESENVOLVIMENTO E DINAMICAS FUNDIARIAS NO BRASIL: \\ A EXPANSÃO DO AGRONEGOCIO DA SOJA E SEUS EFEITOS \\ SOBRE O MEIO RURAL
}

\author{
Sergio Pereira Leite* \\ Valdemar João Wesz Junior"*
}

\section{Resumen}

Este artículo busca presentar el proceso de expansión del agronegocio de granos en las regiones del Cerrado brasilero (sabanas de Brasil). El estudio analiza las modalidades de concentración económica y agraria del sector, con una atención particular sobre las estrategias de las empresas transnacionales (tradings) (orientadas para la creación de un patrón tecnológico que favorece las grandes fincas agrícolas y la utilización de máquinas e implementos agrícolas sofisticados); el apoyo del Estado al acceso del capital (financiamiento rural y renegociación de las deudas de los grandes productores de la agricultura brasilera); las condiciones de acceso a la tierra, etc. El artículo también analiza el impacto de esta expansión y de la concentración económica y agrícola del agronegocio sobre el cerrado, el precio de la tierra, la generación de nuevos conflictos y, de manera más amplia, la capacidad de reproducción de la agricultura familiar.

" Professor do Programa de Pós-Graduação de Ciências Sociais em Desenvolvimento, Sociedade e Agricultura na Universidade Federal Rural do Rio de Janeiro (CPDA/UFRRJ). Endereço: Av. Presidente Vargas, 417/8andar - Centro - Rio de Janeiro/RJ - Cep: 20071-003. Fone: 55 (21) 2224-8577 R. 214. e-mail: sergioleite@ufrrj.br

Doutorando do Programa de Pós-Graduação de Ciências Sociais em Desenvolvimento, Sociedade e Agricultura na Universidade Federal Rural do Rio de Janeiro (CPDA/UFRRJ). Assistente de Pesquisa do Observatório de Políticas Públicas para Agricultura (OPPA/CPDA/UFRRJ). Endereço: Av. Presidente Vargas, 417/8andar - Centro - Rio de Janeiro/RJ - Cep: 20071-003. Fone: 55 (21) 2224-8577 R. 214. email:jwesz@yahoo.com.br 
JEL: Q13, Q18

Palabras clave: Agronegocio - monocultivos - soya - Brasil

\begin{abstract}
This article aims at presenting the expansion process of grains agribusiness in the regions of cerrado (the Brazilian savannas). The study analyses the modalities of economic and land concentration performed by this sector, driving particular attention to transnational companies (tradings) (oriented to the creation of a technological standard which favors the large agricultural organizations and the use of sophisticated agricultural implements and machines); the State support in access to capital (rural funding and renegotiation of debts held by the large producers in Brazilian agriculture); conditions of access to land, etc. The article also analyses the impact caused by expansion and land and economic concentration derived from agribusiness over the cerrado, also, the land price, new conflicts generated and, in a broader sense, the capacity of reproduction of family-run agriculture.
\end{abstract}

JEL: Q13, Q18

Keywords: Agribusiness - monoculture - soy - Brazil 


\section{INTRODUÇÃO}

A partir de 1999, como resultado da adoção de uma política de câmbio flutuante (com a forte desvalorização da moeda brasileira) e da reedição da estratégia de geração de saldos comerciais ancorados na exportação de produtos primários, o Brasil assiste a uma retomada da expansão da sua fronteira agrícola. Conforme o IBGE/PAM (2010), entre as safras de 2001 e 2005 a área plantada com grãos aumentou $22,7 \%$, sendo que, no caso da soja tal ampliação foi ainda mais expressiva, alcançando um crescimento de $40,3 \%$ ( $8 \%$ a.a.). Apesar do acréscimo da produção nacional, do avanço das exportações e da geração de superávits comerciais, esse processo de expansão territorial da produção de monoculturas, realizada em grandes e médios estabelecimentos agropecuários, deu-se paralelamente ao agravamento de problemas sociais, fundiários e ambientais, especialmente nas áreas objeto daquela expansão.

Este artigo tem como objetivo apresentar, grosso modo, alguns resultados desse crescimento da agricultura brasileira em espaços onde ocorre uma forte ampliação da área plantada com grãos. Vale destacar que tal desempenho foi acompanhado por um movimento de concentração econômica e fundiária, em boa parte estimulado pelo Estado brasileiro. O trabalho toma como referência, em particular, as áreas circunscritas às regióes do bioma cerrado, como, por exemplo, o Oeste da Bahia e a metade norte do Mato Grosso, marcadas por um aumento dos preços da terra, pelo surgimento de novos conflitos sociais e ambientais, pela elevação do custo de produção, pela ampliação da área média plantada com grãos e pela forte especialização produtiva.

Para tanto, o estudo analisa a concentração econômica e fundiária no setor da soja - cultura representativa do chamado agronegócio brasileiro -, abordando as estratégias das empresas transnacionais (orientadas para 0 processo de verticalização e integração das atividades agropecuárias à montante e à jusante), o apoio do Estado através da disponibilização de crédito rural (oferta de financiamento e renegociação da dívida dos produtores) e na performance do mercado de terras vis-à-vis as áreas de expansão.

Este trabalho se insere em uma pesquisa maior, intitulada "Sociedade e Economia do Agronegócio: um estudo exploratório" (Heredia et al., 2009), cujo objetivo é analisar em profundidade o processo - social, econômico e 
político - que marca a expansão do agronegócio, a partir de um trabalho de campo realizado nos estados do Mato Grosso, Bahia e Minas Gerais. A pesquisa, coordenada pelos professores Beatriz Heredia (PPGSA/UFRJ), Sergio Leite (CPDA/UFRRJ), Leonilde Medeiros (CPDA/UFRRJ) e Moacir Palmeira (PPGAS/ UFRJ), conta com o apoio do CNPq, da Fundação Ford e da Faperj.

\section{EXPANSÃO DO AGRONEGÓCIO E CONCENTRAÇÃO (FUNDIÁRIA E ECONÔMICA) SETORIAL}

Com a crise internacional no início dos anos 1980 o setor rural viu-se envolto no esforço de geração de superávits na balança comercial, aprofundando sua capacidade de exportação de produtos agroprocessados e gerando divisas canalizadas para o pagamento dos serviços da dívida externa. Apresentando um desempenho sempre positivo no saldo comercial (exportações - importações) ao longo de todo esse período, a agricultura voltou a ocupar nos anos mais recentes, especialmente com a desvalorização do real em 1999, um papel de destaque nessa "ofensiva externa". Atendo-nos aos últimos vinte anos desse processo, examinemos com um pouco mais de atenção algumas dessas mudanças e suas conseqüências para a questão do desenvolvimento rural. Como é sabido, ao longo da década de 1980, o país já assistia uma ocupação das áreas de cerrado, tanto na região Centro-Oeste (Goiás, Mato Grosso do Sul e Mato Grosso), como em Minas Gerais e Bahia com a produção de grãos. Na última década verifica-se, ainda, uma vigorosa expansão da chamada "fronteira" agrícola, incorporando áreas, como aquelas localizadas nos estados do Maranhão, Piauí e Tocantins e outras inscritas na região Amazônica. Isso fica evidente nos mapas apresentados a seguir no Gráfico 1, onde selecionamos a expansão da produção de soja, uma cultura sobejamente reconhecida como representativa do agronegócio. 
Gráfico 1 - Expansão da produção de soja (em toneladas) e a localização das agroindústrias processadoras no Brasil - 1990/ 2008
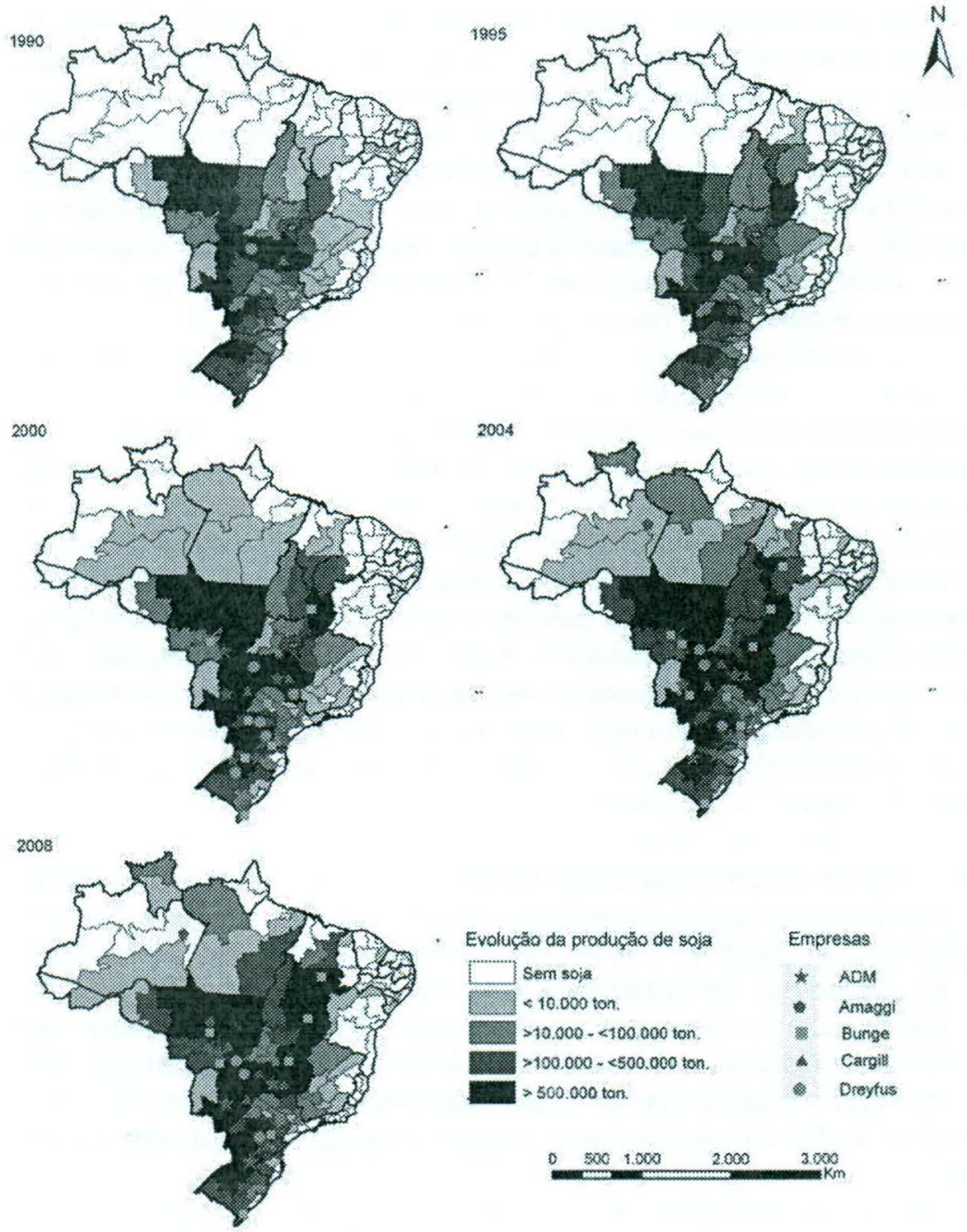

Evoluçăo da produçă̄o da soja

Empresas
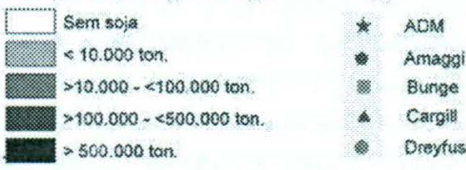

Fonte: IBGE/PAM e Abiove (2010). 
O Gráfico 1 ilustra o intenso processo de espacialização da produção de soja no país, entre 1990 e 2009, anteriormente concentrada na região Sul, para as áreas compreendidas pelos cerrados, seja nos estados da região CentroOeste, seja em direção ao cerrado mineiro ou aos cerrados nordestinos. $\mathrm{Na}$ década atual é possível verificar, ainda, sua expansão para a região amazônica, especialmente nos estados do Amazonas (na região de Humaitá) e do Pará (Sudeste e, em especial, Oeste paraense, na região de Santarém). A tonalidade das cores informa a presença da produção de soja nas micro e mesorregiões brasileiras (do cinza claro, quando a produção local é baixa, ao preto, que reflete uma alta produção concentrada espacialmente, tendo como referência as escalas descritas na legenda da figura) e o seu espraiamento em direção ao norte do país, formando praticamente um "Y", quando consideradas as áreas de maior concentração produtiva.

Devemos salientar, corroborando as informações coletadas em campo, que a expansão da soja não ocorreu de forma isolada: em boa parte dos casos o avanço da cultura ocorreu sobre áreas anteriormente destinadas à criação de gado (ou ainda sobre matas e florestas, como em parte do estado de Mato Grosso e na região amazônica), substituídas posteriormente pela produção de arroz (para "amansar a terra") e, na seqüência, pelo plantio de soja. No Mato Grosso e no Oeste baiano, verificamos, ainda, o aumento da produção de algodão, na esteira da consolidação da produção de soja. No Triângulo Mineiro, com uma produção agrícola (para não mencionar o setor industrial e de serviços - em especial transporte) muito mais diversificada, deve-se atentar igualmente para o plantio de café.

Ainda que o assunto seja objeto de forte polêmica, é possível observar que esta expansão tem gerado protestos de organizações ambientalistas e comunidades nativas, visto que parte da área ocupada pela soja tem sido angariada às custas do desmatamento e/ou do deslocamento forçado de pequenos agricultores ou aldeias indígenas, como pode ser constatado nas chapadas piauienses (Moraes e Vilela, 2003; Schlesinger, 2006). Visão oposta é defendida por outros autores e associações empresariais e de classe do setor agropecuário, e embasa análises como aquelas contidas em Brandão et al. (2006). 


\section{PRESENÇA DAS AGROINDUSTRIAS, CONCENTRAÇÃO EMPRESARIAL E DESLOCAMENTO ESPACIAL}

Em paralelo ao processo de expansão das atividades agrícolas no Brasil tem ocorrido a instalação das empresas agroindustriais, que exercem um papel central sobre as estratégias e o comportamento dos diversos agentes econômicos envolvidos com o setor (Mazzali, 2000). Além disso, a indústria de processamento tem sido o elo central de comando das transformações na agricultura, ditando o seu ritmo de expansão, agregando valor ao produto primário e, principalmente, alavancando as transformações nos padrões de produção e de competitividade do setor (Benetti, 2004).

No Brasil o segmento de esmagamento da soja apresenta um elevado nível de concentração, ocorrido substancialmente pelas fusões e aquisições a partir da abertura comercial no país, pela recentragem estratégica das empresas e pelo seu endividamento diante das condições macroeconômicas adversas. Os dados mostram a intensidade do processo, uma vez que as dez maiores empresas passam de uma participação de $53 \%$ em 1995 , e que por si só já era concentrada, para $80 \%$ em 2005 (ver Tabela 1). É interessante observar ainda que as quatro posições iniciais quase dobraram seu percentual de participação, passando de $31 \%$ para $57 \%$. Além disso, é possível perceber que somente três empresas presentes em 2005 estavam entre as dez primeiras em 1995, o que demonstra uma rápida alteração na estrutura patrimonial e nominal das indústrias de esmagamento.

Em paralelo ao aumento da concentração, a Tabela 1 aponta para a elevação das empresas estrangeiras dentro do país (processo de desnacionalização). Além das agroindústrias transnacionais ocuparem as quatro primeiras posições em $2005,57 \%$ da participação do esmagamento da soja está sob o controle da Bunge, Cargill, ADM e Coinbra/Dreyfus - enquanto que em 1995 as empresas internacionais chegavam a $16 \%$. É importante destacar que nas décadas de 1970 e 1980 o investimento estrangeiro era muito reduzido neste segmento, apontando que a abertura econômica posta pelo Plano Real em 1994 foi central na "internacionalização do agronegócio brasileiro tanto no sentido patrimonial, isto é, da importância crescente do capital estrangeiro na propriedade dos ativos das cadeias agroalimentares, quanto no comercial, vale dizer, do aumento da inserção da produção brasileira de commodities nos circuitos comerciais e produtivos mundiais" (Benetti, 2004, p. 197). 
Tabela 1 - Participação das dez maiores empresas no esmagamento da soja no Brasil entre 1995 e 2005

\begin{tabular}{|c|c|c|c|c|c|c|c|}
\hline \multicolumn{4}{|c|}{1995} & \multicolumn{4}{|c|}{2005} \\
\hline $\begin{array}{l}\text { Colo- } \\
\text { cação }\end{array}$ & Empresa & $\begin{array}{c}\text { Participação } \\
(\%)\end{array}$ & $\begin{array}{c}\text { Origem } \\
\text { do } \\
\text { capital }\end{array}$ & $\begin{array}{l}\text { Colo- } \\
\text { cação }\end{array}$ & Empresa & $\begin{array}{c}\text { Participação } \\
(\%)\end{array}$ & $\begin{array}{c}\text { Origem } \\
\text { do } \\
\text { capital }\end{array}$ \\
\hline $1^{\circ}$ & Ceval & $14 \%$ & Nac. & $1^{\circ}$ & Bunge & $24 \%$ & Inter. \\
\hline $2^{\circ}$ & Santista & $6 \%$ & Inter. & $2^{\circ}$ & ADM & $12 \%$ & Inter. \\
\hline $3^{\circ}$ & Cargill & $6 \%$ & Inter. & $3^{\circ}$ & Cargill & $11 \%$ & Inter. \\
\hline $4^{\circ}$ & Sadia & $5 \%$ & Nac. & $4^{\circ}$ & Coinbra & $10 \%$ & Inter. \\
\hline $5^{\circ}$ & Incobrasa & $5 \%$ & Nac. & $5^{\circ}$ & Incopa & $5 \%$ & Nac. \\
\hline $6^{\circ}$ & G. Lever & $4 \%$ & Nac. & $6^{\circ}$ & Granol & $5 \%$ & Nac. \\
\hline $7^{\circ}$ & Granóleo & $4 \%$ & Nac. & $7^{\circ}$ & Coamo & $4 \%$ & Nac. \\
\hline $8^{\circ}$ & Bianchini & $3 \%$ & Nac. & $8^{\circ}$ & Avipal & $3 \%$ & Nac. \\
\hline $9^{\circ}$ & Perdigão & $3 \%$ & Nac. & $9^{\circ}$ & Bianchini & $3 \%$ & Nac. \\
\hline $10^{\circ}$ & Caramuru & $3 \%$ & Nac. & $10^{\circ}$ & Caramuru & $3 \%$ & Nac. \\
\hline \multicolumn{2}{|l|}{ Total } & $53 \%$ & & \multicolumn{2}{|l|}{ Total } & $80 \%$ & \\
\hline
\end{tabular}

Fonte: Gaspari (2004); Souza (2007).

Além da concentração empresarial no setor de esmagamento e da diminuição das agroindústrias brasileiras neste mercado, tem ocorrido uma nova regionalização das atividades ligadas à produção de óleo e farelo de soja (ver Gráfico 1). Esse deslocamento da capacidade de processamento dos estados do Sul para o Centro-Oeste pode ser evidenciado pelo aumento da participação do Mato Grosso, Goiás e Bahia em detrimento do Rio Grande do Sul, Santa Catarina, São Paulo e Paraná, que compunham até a década de 1990 a "região tradicional". Atualmente a maior capacidade de esmagamento de soja está na região Centro-Norte do Brasil (áreas de fronteira), enquanto que em 2000 elas representavam somente 25\% (Abiove, 2010). Esta conjuntura está atrelada fundamental ao deslocamento da produção da oleaginosa, além da influência do marco regulatório brasileiro (Lei Kandir), da isenção fiscal concedidas pelos estados às empresas e do apoio político oferecido pelos governos. 


\section{ESTRATEGIAS EMPRESARIAIS NAS AGROINDUSTRIAS: INTEGRAÇÃO À MONTANTE E À JUSANTE DAS ATIVIDADES AGROPECUARIAS}

Uma das principais estratégias que tem se difundido entre as empresas envolvidas com o processamento da soja tem sido a integração entre os elos a montante (fertilizantes) e a jusante (esmagamento) da produção agropecuária, isto é, os mesmos grupos atuam tanto na etapa de agroindustrialização da oleaginosa como na produção e distribuição de insumos. Esse tem sido o caso da Bunge, Cargill, ADM e Coinbra/Dreyfus (Grupo ABCD), que apresentam investimentos em ativos e unidades industriais de produção de fertilizantes.

A Bunge e Cargill apresentam um elevadíssimo controle no segmento de fertilizantes, pois somente esses dois grupos passaram a dominar 57,4\% deste mercado em 2009, sendo que a Bunge detém 43,4\% (Saab e Paula, 2008). Apesar da ADM possuir uma menor participação no setor, a sua produção é suficiente para cobrir grande parte dos produtores rurais que detém contratos com a empresa (Souza, 2007). Já a Coinbra/Dreyfus tem a pretensão de produzir 2 milhões de t/ano de fertilizantes no Brasil até 2011, o que significaria uma participação de $8 \%$ no mercado brasileiro. Essas informações apontam que a produção e a comercialização de insumos pelas quatro empresas transnacionais (Grupo $\mathrm{ABCD}$ ) têm sido consideradas como um campo estratégico, visto os crescentes investimentos no setor e a significativa participação destas no mercado brasileiro e mundial.

Para além da produção e venda de insumos e do processamento do grão, as tradings têm se envolvido, complementarmente ao Sistema Nacional de Crédito Rural operado pelo Estado, com a oferta de financiamento (antes da crise financeira internacional de 2008), chegando a cobrir $67 \%$ da produção nacional de soja - em determinadas regiões esse valor é ainda mais expressivo (Rodrigues et. al., 2009).

Esta estratégia de verticalização da produção tem garantido o fornecimento da matéria-prima para as agroindústrias, pois no momento da compra dos fertilizantes pelo agricultor e na aquisição do financiamento já é pré-estabelecida a venda da produção agrícola. Para as esmagadoras isso tem sido de fundamental importância diante da presença simultânea de outros empreendimentos que concorrem pela mesma matéria-prima. Assim, a incerteza do fornecimento de grão pelo agricultor é reduzida no momento em 
que as tradings "amarram" o produtor a contratos de fornecimento, trocando insumos pelas safras futuras (Farina e Zylbersztajn, 1998). Além disso, a integração entre os elos à montante e à jusante tem possibilitado a obtenção de sinergias no transporte, a elevação da margem de lucro, a geração de rendas extras por subsídios governamentais e a complementaridade tecnológica e de marketing entre os segmentos (Souza, 2007, Gaspari, 2004).

\section{PAPEL DO ESTADO E A POLITICA DE FINANCIAMENTO RURAL}

A cadeia da soja, para ficarmos no exemplo acima e reforçando a justificativa da nossa escolha, constitui-se numa das rubricas mais expressivas da pauta de exportações do chamado "macro-setor agrícola" (ainda que as vendas do produto em grão tenham crescido numa velocidade superior aos produtos processados a partir da soja - farelo, óleo, etc. - o que corrobora uma certa especialização nas exportações com menor capacidade de geração de valor adicionado, aumentando o grau de vulnerabilidade externa), o qual representa hoje algo próximo a $40 \%$ do valor das exportações totais. É certo que a recente retomada dos saldos superavitários da balança comercial brasileira tem sido acompanhada, para alguns analistas até impulsionada, pelo movimento das exportações rurais, redundando num aumento da geração de divisas comerciais. Esse movimento, de certa forma, tem justificado, para alguns estudiosos e parte do campo político e midiático, o aprofundamento dessa estratégia. Mesmo que isso se faça às custas de um endividamento crescente do setor patronal e os custos conseqüentes assumidos pelo Estado, ou que, ainda, tal diretriz se constitua a partir de relações de intensa exploração e precarização do trabalho na sua base (ainda que identifiquemos durante nosso trabalho outras formas de apropriação dessas oportunidades de trabalho que não passam necessariamente pelo crivo da "precarização", quebrando uma certa linearidade em voga nas interpretações correntes). Isso nos leva a examinar melhor questões como a forma de intervenção do Estado e as condições nas quais emerge o debate e a questão do agronegócio.

O que nos parece relevante aqui, é destacar a "localização" de tais programas na esfera governamental. Até o presente momento a "problemática agrária" está alocada em ministério próprio (Ministério do Desenvolvimento Agrário, MDA), desvinculada daquele destinado a tratar dos "assuntos agrícolas", ou ainda para "estabelecer o conceito do agronegócio", a cargo do Ministério da Agricultura, Pecuária e Alimentação (MAPA). Essa divisão 
apresenta aspectos positivos e negativos sobre os quais seria desejável uma reflexão mais apurada que escapa aos objetivos do presente texto.

Assim, no que se refere às políticas públicas, parece-nos que um conjunto de esferas e instrumentos possui uma capacidade maior de atuação local e incorpora-se, em maior ou menor grau, no cálculo estratégico dos 'atores' em jogo. Esse conjunto inclui: a) as políticas relativas ao ordenamento territorial e a disputa (em curso ou já 'realizada') em torno da terra; b) as políticas referentes ao trabalho (incluindo o combate ao trabalho escravo) e seu rebatimento sobre as formas e relações existentes e os fluxos migratórios delas derivados; c) as políticas ambientais e os marcos regulatórios que a orientam, introduzindo uma 'nova' variável na composição e representação dos interesses dos segmentos direta e/ou indiretamente envolvidos; d) as políticas de crédito, financiamento e seus constrangimentos - financeiros, tecnológicos e institucionais; e) as políticas de infraestrutura, que materializam num certo sentido a ação do Estado.

Com relação ao tema do financiamento, uma rápida passagem pela política de crédito rural brasileira, deixa explícita a importância de culturas, como a soja, na absorção dos recursos emprestados. Isso pode ser constatado na Figura 2 , onde nota-se que cerca de $1 / 3$ dos valores disponibilizados dirigiramse ao financiamento da soja nos últimos dez anos.

No estado do Mato Grosso, onde a especialização produtiva avançou sobremaneira durante o período 1980-2008 como já foi mostrado no Gráfico 1, a participação da soja no total dos recursos financiados é ainda maior, variando entre $50 \%$ e $75 \%$ no mesmo período (1999-2009). Nessa mesma região, quando analisamos a distribuição do crédito entre agricultores empresariais e agricultores familiares, veremos que os primeiros respondem pela absorção de $93 \%$ dos recursos, em média, na última década, deixando explícita a forte concentração econômica do setor. 
Gráfico 2 - Sistema Nacional de Crédito Rural no Brasil- participação das diferentes culturas no financiamento agrícola - 1999/2009

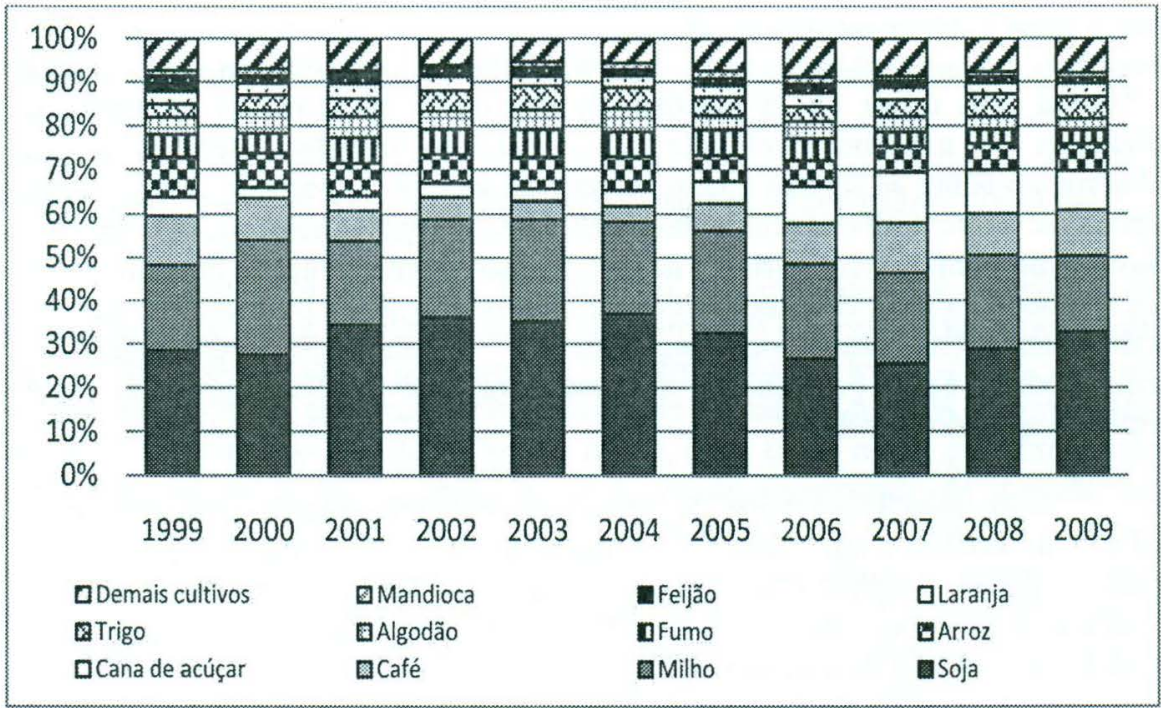

Fonte: Banco Central. Anuário Estatístico do Crédito Rural. Vários anos.

A concentração do crédito em algumas culturas, regiões e tamanhos de estabelecimentos agropecuários, que amparou, em certa medida, a expansão geográfica vista anteriormente, revelou-se ainda onerosa para o próprio Estado, na medida em que parte desses empréstimos não foram pagos pelos tomadores finais, implicando num ônus relativo ao endividamento agrícola e às renegociações derivadas para a prorrogação de prazos e refinanciamento de débitos. 


\section{PERFOMANCE DO MERCADO DE TERRAS VIS-A-VIS AS AREAS DE EXPANSÃO AGRICOLA}

O processo de expansão das áreas produtivas baseadas em monoculturas direcionadas à exportação, examinado até aqui, rebateu, adicionalmente num aumento recente no preço dos imóveis rurais localizados nessas regiões. Primeiramente é necessário observar que, após o final da década de 1990, como comentamos na Introdução, o preço das terras com lavouras dispara significativamente, em termos médios para o caso brasileiro, como podemos constatar pelo Gráfico 3.

Gráfico 3 - Variação nos Preços das Terras (R \$/ha) no Brasil para compra 1994/2006 - valores correntes

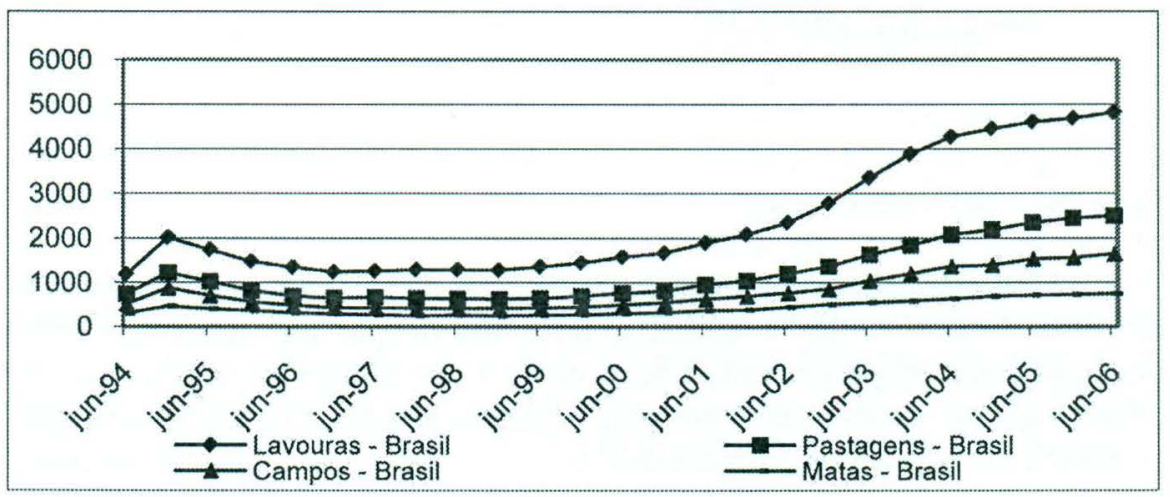

Fonte: Fundação Getulio Vargas.

Esse movimento fica ainda mais evidente nas regiões que estamos trabalhando, isto é, a área compreendida como cerrado brasileiro. Tomaremos como exemplo novamente o caso matogrossense, na região Centro-Oeste do Brasil, ilustrado pela Figura 4. Além das fortes variações observadas no preço de compra e venda das áreas com lavouras, observamos igualmente um acréscimo considerável nas áreas com pastagens, que transformam-se na seqüência em novas áreas abertas para o cultivo de soja e algodão. 
Gráfico 4 - Variação nos Preços da Terras (R\$/ha) do Mato Grosso para compra - 1994/2006 - valores correntes

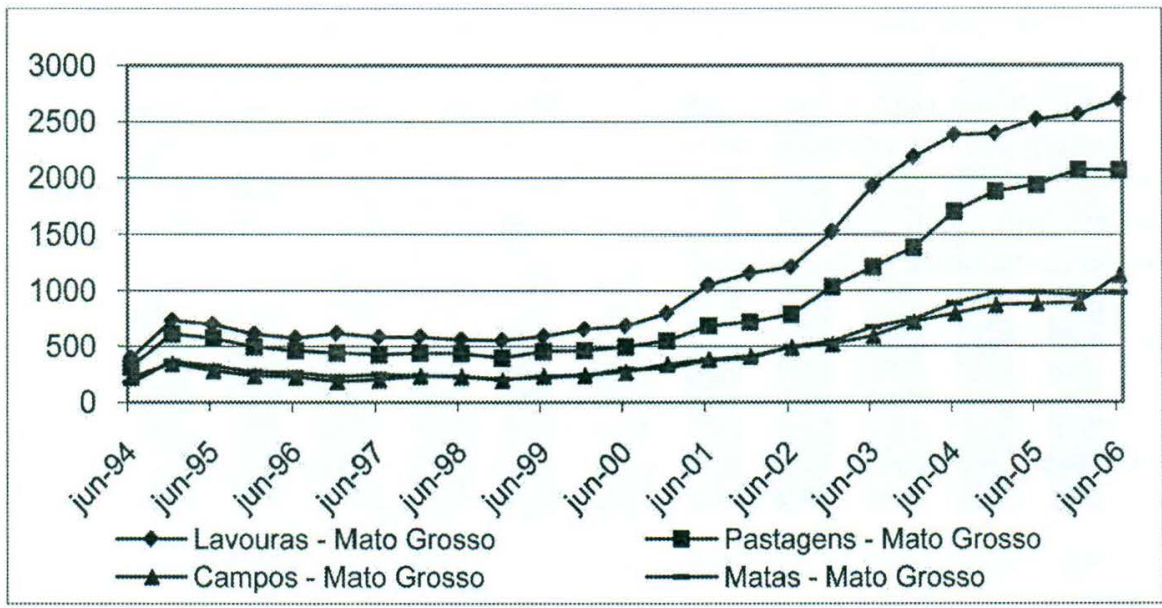

Fonte: Fundação Getulio Vargas.

Em algumas outras regiões, como os cerrados existentes nos estados de Minas Gerais, Goiás e Bahia, a forte valorização das terras tem sido estimulada também pela entrada maciça de novos investimentos na produção de cana-de-açúcar, especialmente nos dois primeiros estados, voltada à fabricação de etanol, no bojo da emergência dos novos combustíveis à base de recursos naturais. 


\section{CONCLUSÕES}

Acreditamos que, é importante ressaltar o "caráter", a intensidade e a velocidade com que tais transformações passaram a ser operadas nas regiões examinadas. No entanto é preciso chamar a atenção para o risco de uma análise "chapada" desse processo, que, à despeito de enunciar o caráter desigual dessas mudanças (além dos seus chamados "efeitos perversos"), desconsidera a complexidade dessas transformações e os diferentes feixes que estas mobilizam. Um dos elementos para o qual buscou-se atentar no presente texto, refere-se ao ainda importante "papel do Estado", que, embora minimizado pelos "intérpretes" da dinâmica do agronegocio, permanece atuante, seja por meio de políticas setoriais relativas ao meio rural/agroindustrial, seja por intermédio de políticas mais globais (como aquela de infraestrutura) ou ainda na tentativa de estabelecer um marco regulatório no campo das relações de trabalho e do meio ambiente.

Da mesma forma, pareceu-nos que uma série de conflitos marcou decisivamente os rumos observados nesse processo de transformações sociais nas últimas décadas. Conflitos esses que se estabeleceram inclusive por meio das lógicas distintas que informam o processo de expansão das agroindústrias nessas regiões, contrapondo os interesses do setor de esmagamento de grãos (e, em decorrência, do setor produtor de carnes brancas) aos interesses dos próprios produtores rurais de médio ou grande porte, que por sua vez se opuseram aos interesses dos agricultores familiares e comunidades nativas, avançando sobre esses novos "territórios" da soja. Entre outros aspectos, isso implicou numa aceleração dos preços no mercado de terras nas regiões de expansão das atividades de monocultura, forçando o deslocamento de um conjunto não desprezível de agricultores de menor porte. 


\section{REFERENCIAS BIBLIOGRAFICAS}

Abiove, (2010), Capacidade de esmagamento da soja no Brasil, São Paulo/SP. Benetti, M. D., (2004), Globalização e desnacionalização do agronegócio brasileiro no pós 1990, Porto Alegre/RS: FEE.

Brandão, A.S.P., Rezende, G.C., Marques, R.W.C. (2006), Crescimento agrícola no período 1999/2004: a explosão da soja e da pecuária bovina e seu impacto sobre o meio ambiente, Economia Aplicada, 2006, Vol. 10 (2), pp. 249-266.

Gaspari, C. A. (2004), O paradigma biotecnológico e o processo de reestruturação das grandes empresas: o movimento das bioindústrias na agroindústria brasileira, Dissertação de Mestrado, Programa de Pós-Graduação em Economia - Universidade Estadual de Maringá, Maringá/PR.

Farina, E. M. M. Q.; Zylbersztajn, D. (1998), Competitividade no Agribusiness Brasileiro, São Paulo/SP: IPEA.

Heredia, B., Palmeira, M., Leite, S. (2009), Sociedade e economia do agronegócio no Brasil, 33\%. Encontro Anual da ANPOCS, Caxambu/MG.

IBGE/PAM, (2010), Produção Agrícola Municipal, Disponível em: http://www.sidraibge.gov.br/bda/pesquisas/pam/ Acessado em junho de 2010.

Mazzali, L. (2000), O processo recente de reorganização agroindustrial: do complexo à organização "em rede", São Paulo/SP: Editora da Unesp.

Moraes, D.; Vilela, S. (2003), Multifuncionalidade e agricultura camponesa nos cerrados piauienses: desafios para a sustentabilidade, In: Carneiro, M., Maluf, R.(orgs.), Para além da produção. Rio de Janeiro: Mauad.

Rodrigues, W. et. al. (2009), Análise das estratégias de financiamento/comercialização dos produtores de soja da região de Santa Rosa do Tocantins, XLVII Congresso Brasileiro de Economia, Administração e Sociologia Rural, Porto Alegre/RS.

Saab, A. A.; Paula, R. de A. (2008), O mercado de fertilizantes no Brasil: diagnóstico e propostas de políticas, In: Revista de Politica Agrícola. Brasília/DF: ano XVII (2), pp. 6-24.

Schlesinger, S. (2006), O grão que cresceu demais: a soja e seus impactos sobre a sociedade e o meio ambiente, Rio de Janeiro: FASE.

Souza, J. F. D. (2007), Integração vertical e financeirização: o caso da agroindústria processadora de grãos no Brasil, Dissertação de Mestrado, Programa de Pós-Graduação em Engenharia da Produção Universidade de São Paulo, São Paulo/SP. 